\title{
PERANCANGAN ULANG TATA LETAK LINI PERAKIAN HEAD LAMP TIPE 2SJ UNTUK MENINGKATKAN KAPASITAS PRODUKSI DI INDUSTRI OTOMOTIF
}

\author{
Danu Sato Ario Putra, Eko Armanto, Ariawan Wahyu Pratomo, Suyadi \\ Jurusan Teknik Mesin, Politeknik Negeri Semarang \\ Email: ariawanwph@yahoo.co.id
}

\begin{abstract}
Abstrak
Industri otomotif umumnya memproduksi perangkat penerangan pada sepeda motor dan mobil. Lamp Assembly/Lamp Assy Department merupakan salah satu departemen di perusahaan ini. Masalah yang timbul dalam studi kasus pada departemen yang dimiliki PT Idonesia Stanlay Electric adalah lini perakitan head lamp 2SJ tidak mampu mencapai target produksi sebanyak 570 pcs/hari. Produk yang dihasilkan lini ini rata-rata 520 pcs/hari. Perlunya perancangan ulang tata letak lini perakitan head lamp 2SJ adalah untuk memberikan alternatif tata letak baru yang mampu mencapai target produksi dan melakukan pengujian menggunakan simulasi Process Simulator 2016. Metode perancangannya yaitu dengan menyetimbangkan lini perakitan head lamp 2SJ dan membagi ulang beban kerja ke setiap stasiun sehingga kapasitas dapat meningkat. Membagi ulang beban kerja mengakibatkan laju aliran bahan berubah dan tata letaknya ikut berubah. Hasil dari penelitian ini menunjukkan bahwa ada dua buah alternatif yang didapat dan memiliki kapasitas produksi lebih tinggi dari kondisi awal lini perakitan head lamp 2SJ. Simulasi yang dilakukan membuktikan analisis penelitian ini yaitu kapasitas dapat meningkat setelah menyetimbangkan lini perakitan kondisi awal. Kapasitas meningkat sebanyak 43 pcs hingga 76 pcs/hari.
\end{abstract}

Kata Kunci : “perancangan tata letak produk”, "kesetimbangan lini”, “kapasitas”, "simulasi”.

\section{Pendahuluan}

PT. Indonesia Stanley Electric adalah cabang perusahaan dari Stanley Electric Co., Ltd. yang berpusat di Negara Jepang. Perusahaan ini memproduksi perangkat penerangan untuk sepeda motor dan mobil. Salah satu departemen di perusahaan ini adalah Lamp Assy/Lamp Assembly Department yang memiliki tugas merakit seluruh komponen yang dihasilkan oleh divisi produksi. Lamp Assembly Department menggunakan sistem just in time dan make to order dalam produksinya. Penyimpanan barang di gudang hanya selama dua hari saja.

Tingginya permintaan dari pemesan membuat PT. Indonesia Stanley Electric, terutama Lamp Assembly Department untuk memiliki strategi yang baik agar dapat meningkatkan produktivitas dan memenuhi permintaan pelanggan dengan hasil berkualitas, tepat waktu dalam pengiriman, dan laba yang maksimal. Salah satu strateginya yaitu dengan membagi tugas merakit dalam tiga seksi perakitan, yaitu perakitan khusus menangani lampu motor, perakitan khusus menangani lampu mobil, dan perakitan khusus menangani Printed Wiring Board (PWB) dan komponen elektrik lainnya untuk bagian lampu yang menggunakan Light Emitting Diode (LED).

Setiap seksi perakitan memiliki beberapa lini perakitan, setiap lini memiliki beberapa stasiun kerja tergantung dari tipe produk yang dihasilkan. Setiap stasiun kerja biasanya diisi oleh satu orang operator sebagai pekerja. Salah satu lini perakitan yang memiliki masalah adalah lini perakitan head lamp 2SJ. Lini perakitan ini memiliki permintaan yang tergolong tinggi yaitu 570 pcs/hari dan hanya menghasilkan rata-rata 520 pcs/hari. Penyebab permasalahan yang ada dikarenakan beban kerja yang ada di setiap stasiun tidak setimbang. Hal ini mengakibatkan peluang penumpukan antar setiap stasiun meningkat dan menyebabkan aliran bahan yang ada tidak stabil dan konstan.

Perancangan tata letak lini perakitan yang baik bisa didapat jika kesetimbangan lini diterapkan, selain itu dengan memperkecil jarak antar stasiun dan menempatkan elemen kerja secara merata dapat meningkatkan 
efisiensi dan kapasitas produksi di lini perakitan (Islam, dkk, 2014). Menurut Raja (2015), lini produksi yang setimbang merupakan lini yang memiliki beban kerja yang adil dan memiliki waktu kerja setiap stasiun yang memiliki perbedaan waktu tidak drastis bahkan tidak memiliki perbedaan waktu stasiun.

Berdasarkan uraian latar belakang diatas, maka dilakukan perancangan ulang tata letak lini perakitan sebagai upaya penyelesaian masalah agar didapat pembagian beban kerja dengan waktu kerja yang tepat, sehingga lini perakitan yang setimbang diharapkan dapat tercapai. Lini perakitan yang setimbang diharapkan dapat meningkatkan kapasitas produksi dari lini perakitan head lamp 2SJ. Sehingga diperoleh judul Perancangan Ulang Tata Letak Lini Perakitan Head Lamp Tipe 2SJ untuk Meningkatkan Kapasitas Produksi di PT. Indonesia Stanley Electric.

Adapun tujuan penelitian ini adalah untuk meningkatkan kapasitas lini perakitan head lamp 2SJ, selain itu tujuan penelitian ini adalah:

- Membuat alternatif rancangan ulang tata letak lini perakitan head lamp 2SJ dan merekomendasikan yang terbaik dengan memperhatikan batasan masalah penelitian.

- Melakukan perbandingan hasil penataan ulang tata letak lini perakitan head lamp tipe 2SJ dengan lini perakitan head lamp 2SJ pada kondisi awal menggunakan pengujian melalui aplikasi simulasi Process Simulator 2016.

\section{Metode Penelitian}

Metode penelitian yang akan digunakan dalam menyelesaikan permasalahan dalam perancangan ulang tata letak lini perakitan head lamp 2SJ di Lamp Assembly Department PT. Indonesia Stanley Electric, akan digambarkan dalam diagram alir di bawah ini.

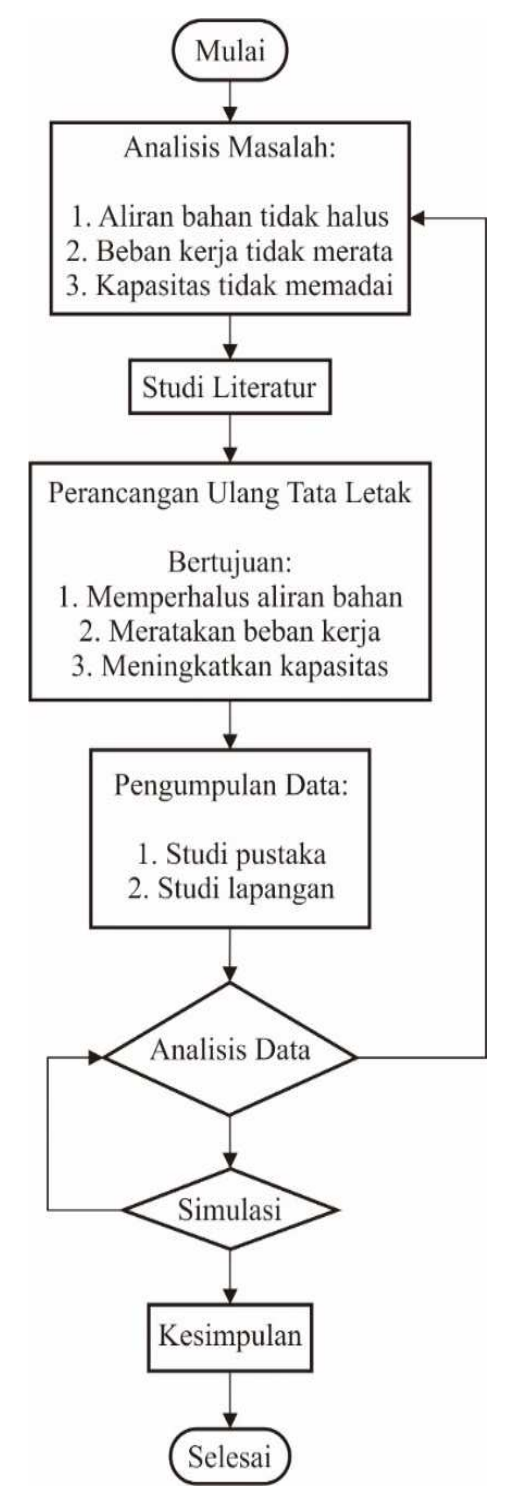

Gambar1. Diagram Alir Penelitian

\subsection{Analisis Masalah}

Analisis masalah dilakukan dengan pengamatan selama melakukan Kuliah Magang Industri. Pengamatan langsung dilakukan di lini perakitan head lamp 2SJ, Lamp Assembly Department untuk mengetahui alur produksi yang terjadi, bentuk tata letak dan aliran bahan yang ada, dan permasalahan apa yang timbul. Diskusi dengan pengawas lini juga dilakukan untuk mengetahui permasalahan lain seperti apa yang akan terjadi jika PT. Indonesia Stanley Electric tidak memenuhi permintaan. 


\subsection{Studi Literatur}

Studi literatur merupakan tahapan untuk mengumpulkan berbagai referensi dan teori yang mendukung penyelesaian permasalahan yang terjadi dan tahapan yang harus dilakukan. Referensi yang digunakan dalam penelitian kali ini meliputi cara melakukan penyeimbangan suatu lini perakitan agar dapat melakukan pembagian ulang beban kerja, sehingga akan didapat tata letak baru yang diharapkan dapat meningkatkan produktivitas.

\subsection{Hipotesis}

Dugaan sementara dalam penelitian ini adalah dengan mengetahui perbedaan beban kerja yang dilakukan oleh setiap stasiun kerja melalui analisis kesetimbangan lini perakitan, dapat digunakan sebagai acuan untuk perancangan ulang tata letak lini perakitan head lamp 2SJ. Pembebanan ulang beban kerja dengan menghilangkan atau memindah beberapa proses pada stasiun kerja diduga dapat mengubah tata letak dan meningkatkan kapasitas produksi lini perakitan head lamp 2SJ.

\subsection{Pengumpulan Data}

Pengumpulan data adalah cara yang dilakukan untuk memperoleh informasi yang dibutuhkan untuk mencapai tujuan suatu penelitian. Pengumpulan data dapat dilakukan melalui studi pustaka dan studi lapangan. Data yang diperoleh saat melakukan studi lapangan dalam penelitian ini yaitu:

- Bentuk tata letak lini perakitan head lamp tipe 2SJ, jumlah stasiun kerja dan operator.

- Jam kerja dalam satu hari.

- Waktu setiap proses yang dilakukan setiap stasiun kerja dalam lini perakitan head lamp tipe $2 \mathrm{SJ}$.
- Waktu siklus lini perakitan head lamp tipe 2SJ dalam membuat satu buah produk.

- Target produksi lini perakitan head lamp tipe $2 \mathrm{SJ}$.

\subsection{Analisis}

Tahap analisis ini merupakan tahap yang menentukan dalam sebuah penelitian. Analisis dilakukan untuk membuktikan kebenaran hipotesis penulis. Analisis yang dilakukan pada penelitian ini yaitu dengan melakukan langkah-langkah dalam merancang ulang tata letak lini perakitan, sehingga diharapkan akan mendapatkan hasil berupa peningkatan kapasitas.

\subsection{Pengujian}

Pengujian dilakukan untuk membuktikan kesesuaian hasil analisis dan perancangan ulang tata letak lini perakitan head lamp tipe 2SJ dengan hipotesis. Pengujian pada penelitian ini menggunakan aplikasi simulasi tata letak Process Simulator dengan membandingkan kapasitas tata letak sebelumnya dengan rancangan tata letak baru lini perakitan head lamp tipe 2SJ.

\section{Hasil dan Pembahasan}

Terlihat dalam Tabel1 bahwa waktu terlama dari stasiun di lini perakitan tersebut adalah stasiun kerja ke 4 yaitu 139,59 detik/pcs untuk menyelesaikan setiap proses/beban kerjanya. Terlihat juga dalam Tabel 4.1 bahwa bila dibuat grafik dan dibandingkan dengan grafik dalam Gambar 2.2 pada pembahsan sebelumnya lini perakitan pada kondisi awal tidak setimbang. Ketidaksetimbangan lini perakitan pada kondisi awal disebabkan beban kerja yang dilakukan oleh operator ke 4 paling besar dibandingkan dengan operator lainnya. Hal ini mengakibatkan terjadinya laju aliran 
bahan dalam lini perakitan tersebut tidak halus dan kontinu. Selain itu mengakibatkan penumpukan material di beberapa stasiun dan tingginya waktu menganggur di beberapa stasiun.

Secara teori, waktu siklus merupakan waktu yang dibutuhkan suatu lini untuk menghasilkan satu buah produk. Waktu siklus dapat diperoleh dari waktu stasiun terlama dalam suatu lini produksi/lini perakitan, dalam masalah kali ini waktu siklus lini perakitan head lamp 2SJ diperoleh dari waktu stasiun ke 4 yaitu 139,59 detik/pcs.

Tabel 1. Proses dan Waktu Setiap Stasiun pada Kondisi Awal

\begin{tabular}{|c|c|c|c|c|c|}
\hline \multirow[b]{2}{*}{ STASIUN } & \multirow{2}{*}{$\begin{array}{l}\text { URUTAN } \\
\text { PROSES }\end{array}$} & \multirow[b]{2}{*}{ NAMA PROSES } & \multicolumn{3}{|c|}{ WAKTU (DETIK) } \\
\hline & & & $\begin{array}{l}\text { KERJA } \\
\text { TANGAN }\end{array}$ & BERJALAN & MESIN \\
\hline \multirow{6}{*}{1} & 1 & SUBASSY BRACKET 1 & 8.20 & & \\
\hline & 2 & SUBASSY BRACKET 2 & 8,88 & & \\
\hline & 3 & INNER LENS CP SETTING & 12,53 & & \\
\hline & 4 & SETTING PWB & 13,64 & & \\
\hline & 5 & SCREW TIGHTENING & 18,78 & & \\
\hline & 6 & VISUAL CHECK & 5,24 & & \\
\hline \multirow{3}{*}{2} & 7 & EXTENTION SUBASSY SETTING & 41,54 & 2,00 & \\
\hline & 8 & INNER LENS FP SUBASSY & 24,96 & 1,00 & \\
\hline & 9 & SCREW TIGHTENING & 20,88 & & \\
\hline \multirow{6}{*}{3} & 10 & HOUSING SUBASSY + PWB SETTING & 31,68 & 1,00 & \\
\hline & 11 & PUSHNUT SETTING & 18,20 & 0,50 & 3,00 \\
\hline & 12 & HEAT STAMP & 7,56 & 0,50 & 20,00 \\
\hline & 13 & HL REFLEKTOR SUBASSY & 38,88 & 3,00 & \\
\hline & 14 & ADIUSTER SETTING & 7,20 & 0,50 & \\
\hline & 15 & AIMING SETTING & 11,88 & 1,00 & 45,00 \\
\hline \multirow{7}{*}{4} & 16 & HL LENS SUBASSY & 23,17 & 1,50 & \\
\hline & 17 & SCREW TIGHTENING & 13,68 & 2,00 & \\
\hline & 18 & AIR BLOW MANUAL & 16,23 & & \\
\hline & 19 & HOTMELT \& PRESS LENS & 29,53 & 1,50 & 54,00 \\
\hline & 20 & SCREW TIGHTENING & 16,56 & 1,00 & \\
\hline & 21 & BULB SETTING & 21,00 & 1,00 & \\
\hline & 22 & COVER PWB SETTING & 10,92 & 1,50 & \\
\hline \multirow{7}{*}{5} & 23 & RUBBER COVER SETTING & 20,00 & 0,50 & \\
\hline & 24 & COOLING & 5,40 & 2,50 & 8,00 \\
\hline & 25 & LEAK TEST & 9,72 & 1,00 & 53,00 \\
\hline & 26 & LIGHTING TEST & 25,20 & 1,00 & 50,00 \\
\hline & 27 & MARKING & 10,08 & & \\
\hline & 28 & DOUBLE CHECK & 18,67 & 1,00 & \\
\hline & 29 & PACKING LORY & 10,32 & 1,80 & \\
\hline
\end{tabular}

Terlihat dalam Tabel 2 bahwa waktu terlama dari stasiun di lini perakitan tersebut adalah stasiun kerja ke 2 yaitu membutuhkan waktu 128,73 detik untuk menyelesaikan setiap proses/beban kerjanya. Apabila dibuat grafik, grafik waktu stasiun alternatif 1 juga lebih setimbang bila dibandingkan dengan grafik waktu stasiun lini perakitan head lamp 2SJ kondisi awal.

\section{Tabel 2. Proses dan Waktu Stasiun} Alternatif 1

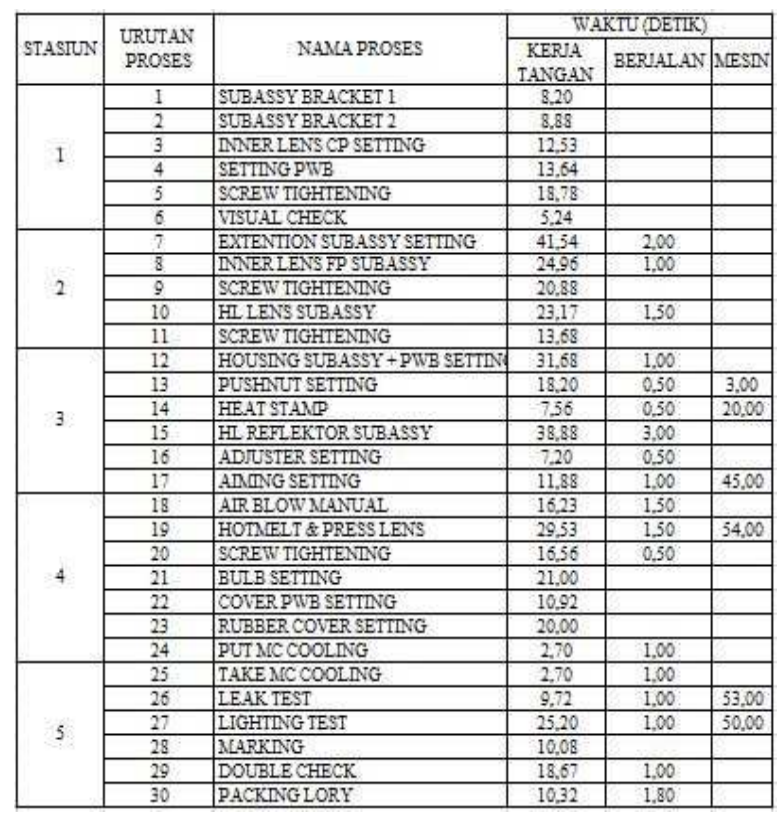

Secara teori, waktu siklus merupakan waktu yang dibutuhkan suatu lini untuk menghasilkan satu buah produk. Waktu siklus dapat diperoleh dari waktu stasiun terlama dalam suatu lini produksi/lini perakitan, dalam masalah kali ini waktu siklus lini perakitan head lamp 2SJ alternatif 1 diperoleh dari waktu stasiun ke 2 yaitu $128,73 \mathrm{detik} / \mathrm{pcs}$.

Tabel 3. Proses dan Waktu Stasiun Alternatif 2

\begin{tabular}{|c|c|c|c|c|c|}
\hline \multirow[b]{2}{*}{ STASIUN } & \multirow[b]{2}{*}{$\begin{array}{l}\text { URUTAN } \\
\text { PROSES }\end{array}$} & \multirow[b]{2}{*}{ NAMA PROSES } & \multicolumn{3}{|c|}{ WAKTU (DETIK) } \\
\hline & & & $\begin{array}{l}\text { KERJA } \\
\text { TANGAN }\end{array}$ & BERJALAN & MESIN \\
\hline \multirow{9}{*}{1} & 1 & SUBASSY BRACKET 1 & 8,20 & & \\
\hline & 2 & SUBASSY BRACKET 2 & 8,88 & & \\
\hline & 3 & INNER LENS CP SETTING & 12,53 & & \\
\hline & 4 & SETTING PWB & 13,64 & & \\
\hline & 5 & SCREW TIGHTENING & 18,78 & & \\
\hline & 6 & VISUAL CHECK & 5,24 & & \\
\hline & 7 & INNER LENS FP SUBASSY & 24,96 & 1,00 & \\
\hline & 8 & SCREW TIGHTENING & 20,88 & & \\
\hline & 9 & ADJUSTER SETTING & 7,20 & 0,50 & \\
\hline \multirow{5}{*}{2} & 10 & EXTENTION SUBASSY SETTING & 41,54 & 2,00 & \\
\hline & 11 & HL LENS SUB.ASSY & 23,17 & 1,50 & \\
\hline & 12 & SCREW TIGHTENING & 13,68 & 2,00 & \\
\hline & 13 & AIR BLOW MANUAL & 16,23 & 1,50 & \\
\hline & 14 & HOTMELT \& PRESS LENS & 15,52 & & 54,00 \\
\hline \multirow{5}{*}{3} & 15 & HOUSING SUBASSY + PWB SETTING & 31,68 & 1,00 & \\
\hline & 16 & PUSHNUT SETTING & 18,20 & 0,50 & 3,00 \\
\hline & 17 & HEAT STAMP & 7,56 & 0,50 & 20,00 \\
\hline & 18 & HL REFLEKTOR SUBASSY & 38,88 & 3,00 & \\
\hline & 19 & AIMING SETTING & 11,88 & 1,00 & 45,00 \\
\hline \multirow{6}{*}{4} & 20 & HOTMELT \& PRESS LENS & 15,52 & & 54,00 \\
\hline & 21 & SCREW TIGHTENING & 16,56 & 0,50 & \\
\hline & 22 & BULB SETTING & 21,00 & & \\
\hline & 23 & COVER PWB SETTING & 10,92 & & \\
\hline & 24 & RUBBER COVER SETTING & 20,00 & & \\
\hline & 25 & PUT MC COOLING & 2,70 & 1,00 & \\
\hline \multirow{6}{*}{5} & 26 & TAKE MC COOLING & 2,70 & 1,00 & \\
\hline & 27 & LEAK TEST & 9,72 & 1,00 & 53,00 \\
\hline & 28 & LIGHTING TEST & 25,20 & 1,00 & 50,00 \\
\hline & 29 & MARKNG & 10,08 & & \\
\hline & 30 & DOUBLE CHECK & 18,67 & 1,00 & \\
\hline & 31 & PACKNNG LORY & 10,32 & 1,80 & \\
\hline
\end{tabular}


Terlihat dalam Tabel 3 bahwa waktu terlama dari stasiun di lini perakitan tersebut adalah stasiun kerja ke 1 yaitu membutuhkan waktu 121,81 detik untuk menyelesaikan setiap proses/beban kerjanya. Apabila dibuat grafik, grafik waktu stasiun pada alternatif 2 juga lebih setimbang bila dibandingkan dengan grafik waktu stasiun lini perakitan head lamp 2SJ kondisi awal.

Secara teori, waktu siklus merupakan waktu yang dibutuhkan suatu lini untuk menghasilkan satu buah produk. Waktu siklus dapat diperoleh dari waktu stasiun terlama dalam suatu lini produksi/lini perakitan, dalam masalah kali ini waktu siklus lini perakitan head lamp 2SJ alternatif diperoleh dari waktu stasiun ke 1 yaitu $121,81 \mathrm{detik} / \mathrm{pcs}$.

Perbedaan waktu siklus lini perakitan kondisi awal dan kondisi setelah dianalisis menjadi kondisi pada alternatif 1 dan alternatif 2 mengakibatkan kapasitas dari lini perakitan tersebut berbeda. Perbedaan kapasitas dikarenakan kapasitas dari lini perakitan diperoleh dengan membagi jumlah waktu kerja dengan waktu siklus yang terjadi.

Gambar 2 di bawah ini merupakan grafik perbandingan kapasitas pada kondisi awal dibandingkan dengan kapasitas alternatif 1 dan alternatif 2 (setelah dianalisis).

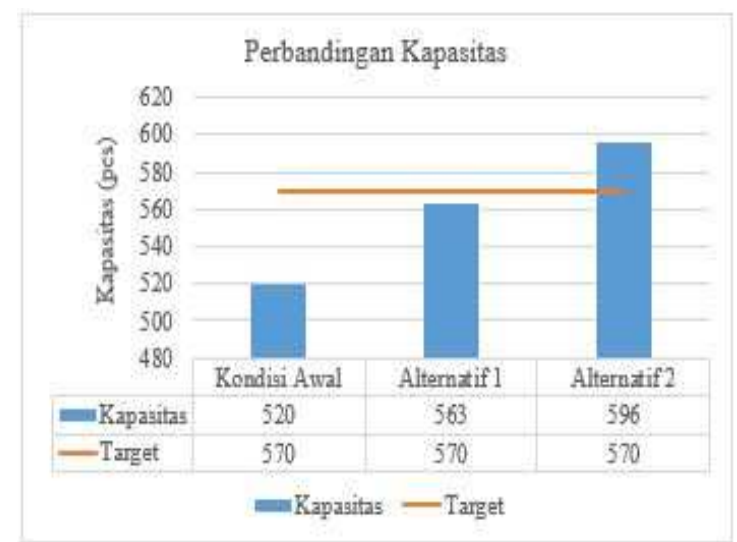

Gambar 2. Grafik

Perbandingan

Kapasitas Lini Perakitan Head Lamp 2SJ
Terlihat dalam grafik pada Gambar 2, bahwa kapasitas pada alternatif 1 dan alternatif 2 mengalami peningkatan dibandingkan dengan kapasitas pada kondisi awal. Kapasitas pada kondisi awal adalah 520 pcs dengan target sebanyak 570 pcs. Kondisi awal tidak dapat memenuhi target dikarenakan beban kerja dalam lini perakitan tidak merata/lini tidak setimbang.

Kapasitas pada alternatif 1 mengalami peningkatan sebanyak 43 pcs dari kapasitas pada kondisi awal. Namun, kapasitas pada alternatif 1 masih tidak mencapai target produksi yang ada. Perbedaan kapasitas antara kondisi awal dan alternatif 1 dikarenakan kesetimbangan pada setiap stasiun kerja lini perakitan berbeda.

Kapasitas tertinggi dari kedua alternatif yaitu kapasitas pada alternatif 2 sebesar 596 pcs. Hal ini dikarenakan lini perakitan pada alternatif 2 lebih setimbang dibandingkan dengan yang ada pada alternatif 1. Selisih antara kapasitas lini perakitan alternatif 2 dengan target produksi yaitu sebanyak 26 pcs. Kapasitas yang melebihi target juga dinilai tidak menguntungkan bagi perusahaan dikarenakan perusahaan ini (PT. Indonesia Stanley Electric) menggunakan sistem make to order dan just in time dalam setiap produksinya. Dikatakan tidak menguntungkan karena sistem make to order dan just in time membuat produk jika ada pesanan dari pihak pemesan dan membuat sesuai dengan jumlah yang diminta oleh pemesan dan langsung dilakukan pengiriman, oleh sebab itu dengan adanya kelebihan jumlah produksi akan mempengaruhi gudang dari perusahaan berupa penumpukan produk. Alternatif untuk menanggulangi terjadinya penumpukan produk di gudang adalah dengan melakukan perawatan berkala pada mesin-mesin produksi yang ada pada lini perakitan head lamp 2SJ. Produk yang menumpuk bisa juga dijadikan sebagai 
tabungan produk head lamp 2SJ jikalau terjadi masalah baru dalam lini perakitan yang menyebabkan target tidak tercapai kembali seperti ketidakhadiran operator atau pembongkaran mesin dikarenakan kerusakan.

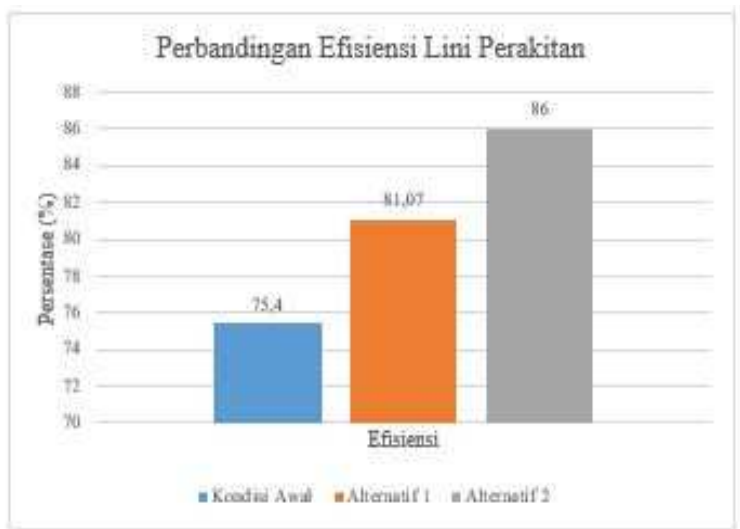

Gambar 3. Grafik Perbandingan Efisiensi Lini Perakitan Head Lamp 2SJ

Seperti yang terlihat pada grafik di atas, efisiensi pada kondisi awal memiliki nilai paling rendah dibandingkan dengan kedua alternatif. Efisiensi pada kondisi awal adalah sebesar 75,4\%. Efisiensi alternatif 1 adalah sebesar $81,09 \%$ dan $86 \%$ untuk alternatif 2 . Peningkatan efisiensi setelah dilakukan pembagian ulang beban kerja pada lini perakitan disebabkan karena lini menjadi lebih setimbang.

Alternatif 2 tentunya menjadi keadaan terbaik pada lini perakitan head lamp 2SJ dikarenakan efisiensi lini perakitan pada alternatif 2 paling tinggi. Semakin tinggi efisiensi yang dimiliki oleh suatu lini, maka biaya yang dikeluarkann akan semakin murah.

\subsection{Tata Letak}

Perubahan tata letak dibuat berdasarkan kesetimbangan lini dengan memperhatikan diagram rakitan, precedence diagram, dan faktor lainnya. Gambar 4, 5, dan 6 berikut ini merupakan gambar tata letak pada kondisi awal, alternatif 1, dan alternatif 2 yang telah dianalisis sebelumnya.

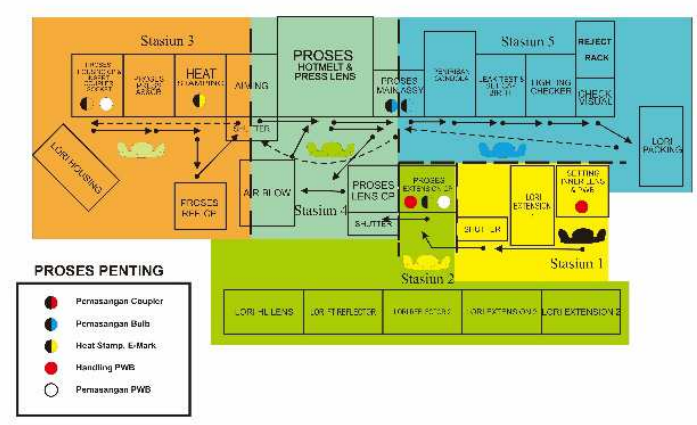

\section{Gambar 4. Tata Letak Lini Perakitan Head Lamp 2SJ Kondisi Awal}

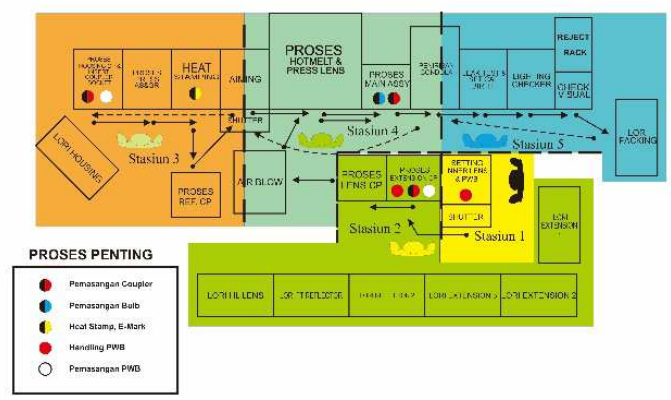

Gambar 5. Tata Letak Lini Perakitan Head Lamp 2SJ Alternatif 1

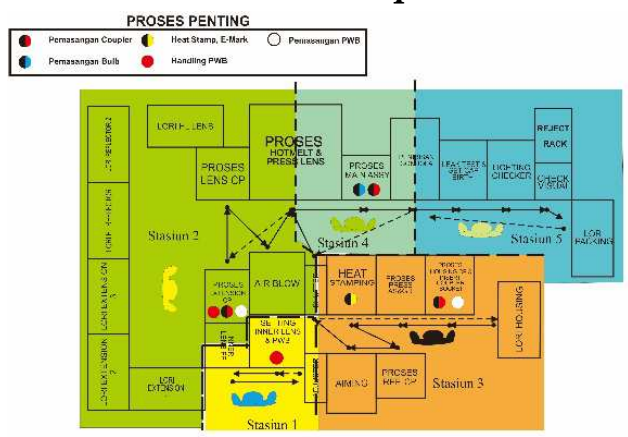

Gambar 6. Tata Letak Lini Perakitan Head Lamp 2SJ Alternatif 2

Luas tanah tata letak lini perakitan pada kondisi awal dan pada alternatif 1 adalah 44 meter $^{2}$ dan 42 meter $^{2}$ untuk alternatif rancangan tata letak lini perakitan. Selisih luas 2 meter $^{2}$ dari kedua tata letak tersebut tidak berpengaruh dengan kapasitas lini perakitan. Aliran bahan yang dilakukan oleh operator setiap stasiun dibuat dan disesuaikan dengan beban kerja/proses yang terjadi dan juga berdasarkan diagram rakitan dan precedence diagram dari lini perakitan head lamp 2SJ. 


\subsection{Simulasi}

Hasil dari simulasi yang telah dilakukan terlihat pada Gambar 4.6, 4.7, dan 4.8 berikut ini. Waktu yang digunakan adalah waktu produksi pada shift 1 yaitu selama 460 menit.

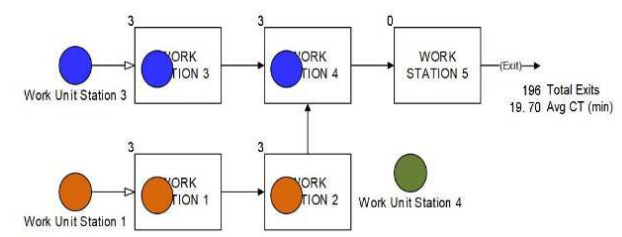

Gambar 7. Hasil Simulasi Kondisi Awal

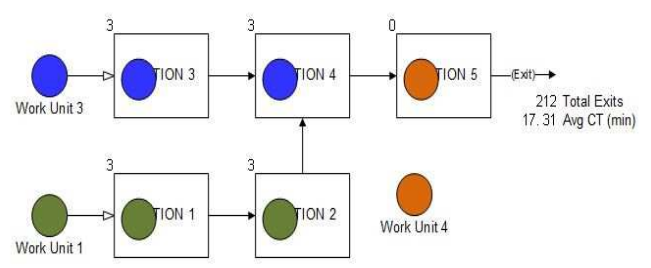

Gambar 8. Hasil Simulasi Alternatif 1

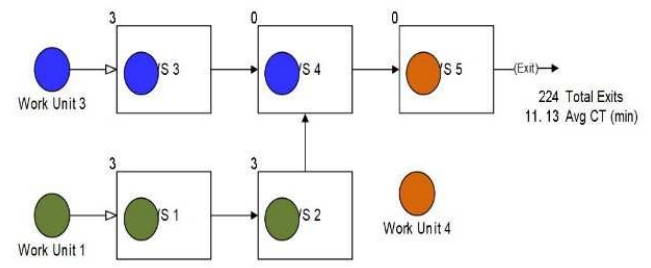

Gambar 9. Hasil Simulasi Alternatif 2

Hasil dari simulasi yang telah dilakukan terlihat pada gambar bahwa kapasitas alternatif 2 rancangan lini perakitan head lamp 2SJ lebih tinggi dari kondisi lini perakitan lainnya. Kapasitas alternatif 2 rancangan lini perakitan head lamp 2SJ menghasilkan produk sebanyak 224 pcs selama 460 menit, sedangkan alternatif 1 dari rancangan lini perakitan head lamp 2SJ hanya menghasilkan 212 pcs dalam 460 menit. Kapasitas lini perakitan head lamp 2SJ pada kondisi awal menghasilkan produk paling sedikit yaitu sebanyak 196 pcs selama 460 menit. Hasil simulasi tersebut menunjukkan bahwa, perancangan ulang lini perakitan dengan melakukan pembagian ulang beban kerja ke setiap stasiun secara merata dan setimbang dapat meningkatkan kapasitas lini perakitan tersebut.

\section{Kesimpulan}

Seperti yang diharapkan, perancangan ulang tata letak dengan melakukan pembagian ulang beban kerja yang ada di dalam stasiun kerja secara merata mampu meningkatkan kapasitas produksi dan efisiensi dari lini perakitan. Setelah dilakukan analisis dan pembahasan pada bab sebelumnya, dapat ditarik kesimpulan:

- Alternatif rancangan tata letak lini perakitan head lamp 2SJ yang didapat ada dua buah alternatif. Alternatif 1 dari rancangan tata letak lini perakitan head lamp 2SJ memiliki kapasitas 563 pcs/hari. Efisiensi dari alternatif 1 rancangan lini perakitan head lamp 2SJ sebesar 81,07\% dan membutuhkan luas tanah sebesar 44 meter $^{2}$. Alternatif 2 dari rancangan tata letak lini perakitan head lamp 2SJ memiliki kapasitas 596 pcs/hari. Efisiensi dari alternatif 2 yaitu $86 \%$ dan membutuhkan tanah seluas 42 meter $^{2}$. Alternatif 2 lebih direkomendasikan sebagai rancangan tata letak yang baru dikarenakan alternatif 2 mampu mencapai target produksi dari lini perakitan head lamp 2SJ sebesar 570 pcs.

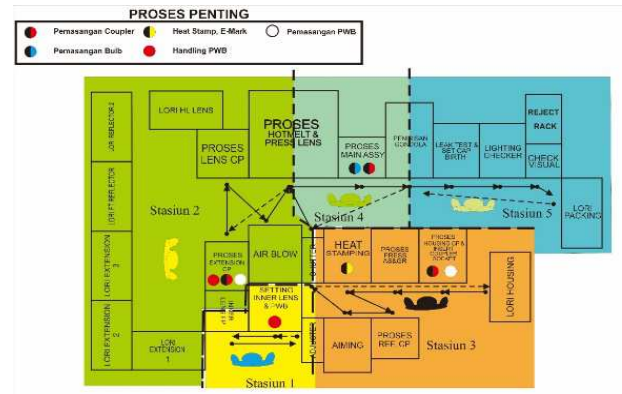

\section{Gambar 10 Tata Letak Lini Perakitan Head Lamp 2SJ Alternatif 2}

- Hasil dari pengujian kedua alternatif menggunakan Process Simulator 2016 menunjukkan bahwa kapasitas produksi dapat meningkat. Waktu produksi yang digunakan dalam melakukan simulasi 
adalah selama satu shift pada shift 1 yaitu 460 menit. Kapasitas yang dapat dicapai dari alternatif 1 adalah sebanyak 212 pcs dan 224 pcs untuk alternatif 2. Hal ini membuktikan hasil analisis yang menunjukkan bahwa kapasitas produksi pada alternatif 2 merupakan yang tertinggi dan mampu mencapai target produksi dalam satu hari.

\section{Daftar Pustaka}

- Adnan, A. N., Arbaai, N. A. \& Ismail, A., 2016. Improvement of Overall Efficiency of Production Line by Using Line Balancing. ARPN Journal of Engineering and Applied Sciences, XI(12), pp. 7752-7758.

- Amardeep, Rangaswamy, T.\& J, G., 2013. Line Balancing Of Single Model Assembly LINE. International Journal of Innovative Research in Science, II(5), pp. 1678-1680.

- Apple, J. M., 1990. Tata Letak Pabrik dan Pemindahan Bahan. 3rd penyunt. Bandung: ITB.
- Hadiguna, R. A. \& Setiawan, H., 2008. Tata Letak Pabrik. 1st penyunt. Yogyakarta: Penerbit ANDI.

- Heizer, J. \& Render, B., 2008. Operations Management. 9th penyunt. New Jersey: Pearson Education, Inc..

- Islam, M. M., Mohiuddin, H., Mehidi, S. H. \& Sakib, N., 2014. An Optimal Layout Design in an Apparel Industry by Appropriate Line Balancing: A Case Study. Global Journal of Research in Engineering: $G$ Industrial Engineering, XIV(5), pp. 35-44.

- Kumar, N. \& Mahto, D., 2013. Assembly Line Balancing: A Review of Developments and Trends in Approach to Industrial Application. Global Journal Of Researches In Engineering, XIII(2), pp. 29-50.

- Raja, R., 2015. Assembly Line Design and Balancing. 1st ed. Gothenburg: Chalmers University Of Technology 